\title{
Intravenous Thrombolysis in Posterior Cerebral Artery Infarctions
}

\author{
L. Breuer ${ }^{a} \quad$ H.B. Huttner ${ }^{a} \quad$ K. Jentsch ${ }^{a} \quad$ C. Blinzler ${ }^{a} \quad$ K. Winder $^{b} \quad$ T. Engelhorn $^{b}$ \\ M. Köhrmann ${ }^{a}$ \\ Departments of a Neurology and ${ }^{\mathrm{b}}$ Neuroradiology, University of Erlangen-Nuremberg, Erlangen, Germany
}

\section{Key Words}

Ischemic stroke $\cdot$ Intravenous thrombolysis $\cdot$ Posterior cerebral artery

\begin{abstract}
Background: Approximately 5-10\% of all acute ischemic strokes (AIS) occur in the territory of the posterior cerebral artery (PCA). Little is known about intravenous thrombolysis (IVT) in this infarct subgroup in terms of outcome and intracerebral hemorrhage rates. The aim of our study was to evaluate differences between supratentorial PCA infarcts and anterior circulation infarcts regarding baseline characteristics, stroke severity, outcome, safety and clinical findings, which would implicate a change in the existing thrombolysis practice in patients with PCA stroke. Methods: All patients with AIS in the supratentorial PCA territory receiving IVT between 01/2006 and 01/2010 were selected from the Erlangen Thrombolysis Database (group $1, \mathrm{n}=21$ ). They were compared to all IVT patients with strokes in other supratentorial vascular territories over the same period of time (group 2, $\mathrm{n}=398$ ). Baseline demographic data, as well as clinical and laboratory findings were analyzed. The outcome was assessed using the modified Rankin Scale at 3 months. Results: Only serum glucose levels at baseline (110.5 \pm 36.1 vs. 127.2 $\pm 48.2 \mathrm{mg} / \mathrm{dl} ; \mathrm{p}=0.036$ ) and the baseline National Institutes
\end{abstract}

of Health Stroke Scale score (median 6.5 vs. 9; $p=0.016$ ) were significantly lower in group 1 compared to group 2. Favorable clinical outcome (57.1 vs. $48.6 \% ; p=0.445$ ) and intracerebral hemorrhage rates ( 4.8 vs. $4 \% ; p=1.000$ ) were comparable in both groups. Conclusions: No substantial differences were found between supratentorial PCA and anterior circulation infarcts. Our data on safety and efficacy support the present common thrombolysis practice in supratentorial PCA infarct patients, though an indication for IVT should rather be based on the existence of functionally disabling deficit than merely on the National Institutes of Health Stroke Scale.

Copyright $\odot 2011$ S. Karger AG, Basel

\section{Introduction}

Infarcts in the territory of the posterior cerebral arteries (PCA) constitute for approximately $5-10 \%$ of all ischemic infarcts [1]. Up to two thirds of all PCA infarcts (PCAI) are pure superficial infarcts [2-5], while thalamic involvement is expected in 20-30\% [6-12]. Several studies have analyzed the variety of neurological symptoms caused by PCAI as well as differing etiological mechanisms and clinical outcome in this infarct subgroup $[2,4,5,13,14]$. Yet, data on patients with PCAI re-

\section{KARGER}

Fax +41613061234 E-Mail karger@karger.ch www.karger.com
(C) 2011 S. Karger AG, Basel

$1015-9770 / 11 / 0315-0448 \$ 38.00 / 0$

Accessible online at:

www.karger.com/ced
Dr. Lorenz Breuer

Department of Neurology, University of Erlangen-Nuremberg

Schwabachanlage 6

DE-91054 Erlangen (Germany)

Tel. +49 9131854 4546, Fax +49 9131853 6597, E-Mail lorenz.breuer@ uk-erlangen.de 
ceiving intravenous thrombolysis (IVT) is limited, for different reasons. First, previous randomized IVT stroke trials focused on patients with anterior circulation stroke [15-17] and ischemic strokes in the posterior circulation are still excluded from many acute treatment trials. Second, typical functional deficits of PCAI are often considered not disabling in the acute phase and the National Institutes of Health Stroke Scale (NIHSS) score underestimates the severity of PCAI symptoms, as complete homonymous hemianopia accounts for only 2 NIHSS points but severely affects the quality of life (e.g. driving, reading, watching TV). For these reasons, IVT is often not initiated. However, if IVT is applied, differentiation is rarely made between supratentorial PCAI and anterior circulation strokes in the present clinical routine. This retrospective study compared IVT patients with ischemic infarcts in the supratentorial PCA territory to those with anterior circulation infarcts. We aimed to evaluate whether differences exist between these 2 groups regarding baseline characteristics, stroke severity, outcome, safety, mortality, clinical and imaging findings, which would implicate a change in the existing thrombolysis practice in patients with PCA stroke.

\section{Methods}

\section{Patient Selection and Treatment}

The Erlangen Stroke and Thrombolysis Database is a prospective database of all patients with acute ischemic stroke (AIS) at our institution (University Hospital Erlangen, Erlangen, Germany). It contains baseline demographic and stroke-related data as well as treatment specifics and imaging information for each stroke patient who underwent thrombolysis. All patients treated with IVT between 01/2006 and 01/2010 were analyzed $(n=457)$. In this study, we compared patients with AIS in the supratentorial PCA territory (cortical infarctions with and without sole additional thalamic involvement; group $1, \mathrm{n}=21$ ) to all patients with AIS in the anterior circulation [middle cerebral artery (MCA) territory and anterior cerebral artery (ACA) territory] receiving thrombolysis over the same period of time (group $2, n=398$ ). The study focused on isolated supratentorial PCAI since clinical differentiation from anterior circulation strokes can be difficult and treatment is similar. In contrast, infratentorial strokes involving the midbrain as well as cerebellar and brainstem infarcts are clinically distinct and often lead to other treatment approaches. Therefore, they were excluded from this study $(n=38)$. Differences between group 1 and group 2 regarding demographics, cerebrovascular risk factors, etiological stroke causes (TOAST classification) [18], clinical features, laboratory and neuroimaging data, complications and outcome were analyzed.

Thrombolysis and Neuroimaging Protocol

All patients were treated and monitored in our stroke unit according to European guidelines [19]. According to international guidelines [19, 20], IVT was not restricted by a certain lower NIHSS limit. Independent of the NIHSS score at admission, patients needed to have a disabling syndrome in the judgment of the treating stroke physician in order to be eligible for IVT [21]. Simple functional tests (i.e. walking, buttoning up trousers, reading, writing, phoning) are carried out in the emergency room to determine the functional impact of the symptom in borderline cases. In addition to standard CT-based treatment within the 3-hour time window, multimodal CT and an MRI mismatch-based algorithm for patients within an extended or unknown time window are used in our institution, as described elsewhere [22]. Infarct allocation to the particular vessel territory and evaluation of intracranial hemorrhage were done based on initial imaging as well as on the 24- to 36-hour control imaging (CT or MRI).

\section{Evaluation of Outcome and Safety}

The NIHSS score was recorded by a stroke neurologist certified for NIHSS evaluation at baseline and 3 times per day throughout the hospital stay. The outcome at 90 days was assessed using the modified Rankin Scale (mRS) evaluated by a neurologist as part of the general database independently from the present study using a semi-structured interview either in person or by telephone. A considerable proportion of patients receiving thrombolysis had a pre-stroke $\mathrm{mRS}>1$. Therefore, favorable clinical outcome was defined as an $\mathrm{mRS}$ of $0-2$ and/or clinical recovery to the pre-stroke mRS. Asymptomatic (aICH) and symptomatic intracerebral hemorrhage (sICH) were defined according to the European Cooperative Acute Stroke Study III criteria [17].

Statistical Analysis

Statistical analyses were performed using the 'SPSS' software package (version 18.0, SSPS Inc.). All data were tested for normality and are given as median and range or the mean $\pm \mathrm{SD}$, as appropriate. Categorical variables are presented as frequencies and percentages. Groups of patients with AIS in the PCA territory and patients with AIS in other territories were compared using the Mann-Whitney U test, $\chi^{2}$ test and Fisher's exact test.

\section{Results}

During the time period of this study, 457 patients received IVT. A total of 59 (12.9\%) patients had posterior circulation strokes partly involving the midbrain as well as the cerebellum or brainstem. The PCA territory was involved in $38(8.3 \%)$ patients, and supratentorial PCAI occurred in 21 (4.6\%) patients (group 1).

\section{PCAI: Clinical Symptoms and Baseline Characteristics}

The frequency of different clinical symptoms of the PCAI patients treated with IVT is given in table 1. Characteristics for all patients (PCAI/MCA/ACA infarcts) and for groups 1 and 2 are presented in table 2 . The median age was 73 years (interquartile range $63-81$ ), and $55.4 \%$ were men. The prevalence of cardiovascular risk factors was high. There were no statistically significant differ- 
ences between the 2 groups regarding age, sex, cardiovascular risk factors, blood pressure, cholesterol, international normalized ratio, platelet count, hemoglobin $\mathrm{A}_{1 \mathrm{c}}$ and inflammation markers such as C-reactive protein and white blood cell count at baseline. Furthermore, both groups were comparable regarding stroke etiology, previous prophylactic treatment and time from symptom onset to thrombolysis. The median baseline NIHSS score was significantly lower in group 1 than in group 2 (6.5 vs. 9; $\mathrm{p}=0.016)$. The median NIHSS at $24 \mathrm{~h}$ still showed a trend towards less neurological impairment in group 1 ( 3.5 vs. $5 ; \mathrm{p}=0.079$ ), and at discharge, no statistically significant difference could be detected (median NIHSS, 3 vs. $4 ; \mathrm{p}=0.202$ ). Further, serum glucose levels at baseline $[110.5 \pm 36.1 \mathrm{mg} / \mathrm{dl}$ (group 1) vs. $127.2 \pm 48.2 \mathrm{mg} / \mathrm{dl}$ (group 2); $\mathrm{p}=0.036$ ] between the 2 groups were significantly different. A fetal origin of the PCA was identified in 4 patients (19\%) of group 1.

\section{Outcome, Safety and Mortality}

The length of hospital stay ( 8 days, range $6.5-10$, vs. 8 days, range $6-12 ; \mathrm{p}=0.477)$, favorable clinical outcome at day 90 ( 57.1 vs. $48.6 \%$; $\mathrm{p}=0.445$ ), intracranial bleeding rates (sICB: 0 vs. $3.5 \%, \mathrm{p}=0.632$; aICH: 9.5 vs. $6.8 \%, \mathrm{p}=$ 0.649 ) and mortality ( 0 vs. $8.8 \%$; $\mathrm{p}=0.240$ ) were comparable in group 1 and group 2 (table 3 ).

\section{Discussion}

Little is known about IVT in patients with supratentorial PCAI in terms of baseline characteristics, stroke severity, clinical outcome, ICH rates and length of hospital stay. Pivotal randomized IVT stroke trials focused on anterior circulation stroke [15-17] and there is no systematic analysis of thrombolysis in isolated PCAI. Therefore, it is unknown whether IVT in this infarct subgroup differs from treatment of anterior circulation infarcts. Several authors have investigated the heterogeneous clinical patterns, topography, etiological causes, long-term functional outcome, intracerebral bleeding and mortality of PCAI in larger case series $[1,4,6,8,11,12,23-25]$. However, none of these authors clearly differentiated between PCAI patients who received tissue plasminogen activator and those who were not treated with thrombolysis.

Our findings with $8.3 \%$ overall PCA involvement and $4.6 \%$ isolated supratentorial PCAI correspond well with pre-existing data (5-10\%) [1]. Thrombolysis in supratentorial PCAI is rare because the corresponding symptoms are often underestimated and not primarily considered
Table 1. Clinical symptoms in PCA patients $(\mathrm{n}=21)$

\begin{tabular}{lrr}
\hline Clinical symptoms & \multicolumn{2}{c}{ PCA strokes } \\
\cline { 2 - 3 } & $\mathrm{n}$ & $\%$ \\
\hline Homonymous hemianopia & 14 & 66.7 \\
Facial palsy & 11 & 52.4 \\
Aphasia & 8 & 38.1 \\
Dysarthria & 6 & 28.6 \\
Head deviation and/or gaze palsy & 4 & 19.0 \\
Neglect & 2 & 9.5 \\
\hline
\end{tabular}

Patients can have combinations of symptoms.

for IVT by the treating physician. Furthermore, affected patients are frequently not aware of their symptoms, or symptom recognition is delayed. On the other hand, unintentional IVT in PCAI patients can occur because differentiation between posterior infarctions and anterior circulation infarcts in the primary emergency room setting may be difficult (see case presentation in fig. 1). Maulaz et al. [26] described PCA strokes mimicking anterior stroke in $17.8 \%$. Especially in the case of combined superficial and deep PCA strokes which occur in up to $38 \%$ [3, $6,12,23,27,28]$, differentiation from MCA/ACA strokes remains challenging because of existing aphasic symptoms, predominant hemiparesis, neglect and sensory deficits. Additional affection of lateral thalamic structures, sometimes combined with thalamocapsular edema, can cause hemiparesis via (reversible) impairment of the pyramidal tracts $[6-8,12]$. Moreover, memory dysfunction and other neurophysiological defects may complicate the examination of these patients $[2,3,14]$.

In our study, most analyzed aspects like age, sex, cerebrovascular risk factors, vital parameters and laboratory results did not show significant differences between groups 1 and 2. Only glucose level at baseline which is known as an independent predictor for higher bleeding risk and worse clinical outcome [29-32] was lower in PCA stroke patients. However, sICH/aICH rates and good clinical outcome were similar in both groups and comparable to the large randomized trials [17, 33, 34]. None of the PCA stroke patients died during the hospital stay, which is consistent with PCA stroke mortality rates $(0-7 \%)$ in the literature $[3,6,14,23,28,35]$.

Four of our PCA stroke patients (19\%) showed a fetal origin of the PCA, and as such, the infarction was attributable to the anterior circulation. This is comparable to the results of de Monyé et al. [36] who reported this vessel 
Table 2. Baseline and outcome characteristics

\begin{tabular}{|c|c|c|c|c|}
\hline & $\begin{array}{l}\text { All infarcts } \\
(\mathrm{PCA} / \mathrm{MCA} / \mathrm{ACA}) \\
(\mathrm{n}=419)\end{array}$ & $\begin{array}{l}\text { PCAI } \\
(n=21)\end{array}$ & $\begin{array}{l}\text { MCA/ACA } \\
\text { infarcts } \\
(n=398)\end{array}$ & $\begin{array}{l}\mathrm{p} \\
\text { values }\end{array}$ \\
\hline Median age, years [range] & $73[63-81]$ & $72[62.5-80]$ & $73[63-81]$ & 0.575 \\
\hline Sex, male & $232(55.4)$ & $15(71.4)$ & $217(54.5)$ & 0.129 \\
\hline \multicolumn{5}{|l|}{ Risk factors } \\
\hline Hypertension & $347(82.8)$ & $19(90.5)$ & $328(82.4)$ & 0.400 \\
\hline Hypercholesterolemia & $228(54.4)$ & $14(66.7)$ & $214(53.8)$ & 0.247 \\
\hline Diabetes & $142(33.9)$ & $9(42.9)$ & $133(33.4)$ & 0.373 \\
\hline Coronary artery disease & $98(23.5)$ & $7(33.3)$ & $91(23)$ & 0.293 \\
\hline Atrial fibrillation & $182(43.4)$ & $8(38.1)$ & $174(43.7)$ & 0.658 \\
\hline Previous stroke & $70(16.7)$ & $3(14.3)$ & $67(16.9)$ & 0.786 \\
\hline Nicotine & $57(13.6)$ & $4(19)$ & $53(13.3)$ & 0.508 \\
\hline Previous myocardial infarction & $42(10)$ & $1(4.8)$ & $41(10.8)$ & 0.504 \\
\hline Peripheral artery disease & $45(10.8)$ & $2(9.5)$ & $43(10.8)$ & 1.000 \\
\hline Systolic blood pressure, $\mathrm{mm} \mathrm{Hg}$ & $160.3 \pm 25.1$ & $159.5 \pm 23.5$ & $160.2 \pm 25.5$ & 0.761 \\
\hline Diastolic blood pressure, $\mathrm{mm} \mathrm{Hg}$ & $87.8 \pm 16.3$ & $85.1 \pm 15.9$ & $87.9 \pm 16.2$ & 0.521 \\
\hline Temperature, ${ }^{\circ} \mathrm{C}$ & $36.9 \pm 0.61$ & $36.8 \pm 0.52$ & $36.9 \pm 0.62$ & 0.596 \\
\hline \multicolumn{5}{|l|}{ Blood parameters } \\
\hline Glucose at baseline, $\mathrm{mg} / \mathrm{dl}$ & $126 \pm 48$ & $110 \pm 36$ & $127 \pm 48$ & 0.036 \\
\hline Cholesterol at baseline, $\mathrm{mg} / \mathrm{dl}$ & $195 \pm 47$ & $202 \pm 32$ & $195 \pm 48$ & 0.477 \\
\hline International normalized ratio & $1.06 \pm 0.14$ & $1.02 \pm 0.11$ & $1.06 \pm 0.14$ & 0.138 \\
\hline White blood cell count, $\times 10^{3} / \mu \mathrm{l}$ & $9.1 \pm 3.4$ & $8.4 \pm 2.2$ & $8.9 \pm 2.35$ & 0.238 \\
\hline Platelet count, $\times 10^{3} / \mu \mathrm{l}$ & $255 \pm 93$ & $238 \pm 62$ & $256 \pm 100$ & 0.650 \\
\hline Hemoglobin $\mathrm{A}_{1 \mathrm{c}}$ & $6.2 \pm 1$ & $5.9 \pm 0.7$ & $6.2 \pm 1$ & 0.413 \\
\hline C-reactive protein at baseline, $\mathrm{mg} / \mathrm{l}$ & $12.3 \pm 25.0$ & $6.8 \pm 9.9$ & $11.9 \pm 24.7$ & 0.270 \\
\hline \multicolumn{5}{|c|}{ Previous prophylactic treatment $(\mathrm{n}=415)$} \\
\hline ASA & $152(36.4)$ & $8(38.1)$ & $144(36.3)$ & 1.000 \\
\hline Clopidogrel & $24(5.7)$ & $4(19)$ & $20(5)$ & 0.026 \\
\hline ERDP/ASA & $5(1.2)$ & 0 & $5(1.3)$ & 1.000 \\
\hline Oral anticoagulation & $25(6.0)$ & 0 & $25(6.3)$ & 0.388 \\
\hline No previous antiplatelet treatment & $209(50)$ & $9(42.9)$ & $200(50.4)$ & 0.655 \\
\hline \multicolumn{5}{|l|}{ Median NIHSS score [range] } \\
\hline Baseline & 9 [0-27] & $6.5[2-15]$ & $9[0-27]$ & 0.016 \\
\hline $24 \mathrm{~h}$ & $5[0-28]$ & $3.5[0-19]$ & $5[0-28]$ & 0.079 \\
\hline Discharge & $4[0-28]$ & $3[0-22]$ & $4[0-28]$ & 0.202 \\
\hline \multicolumn{5}{|l|}{ TOAST criteria } \\
\hline Large vessel & $32(7.6)$ & $1(4.8)$ & $31(7.8)$ & 1.000 \\
\hline Embolic & $186(44.4)$ & $9(42.9)$ & $177(44.5)$ & 1.000 \\
\hline Micro/lacunar & $2(0.5)$ & 0 & $2(0.5)$ & - \\
\hline Other & $21(5)$ & $1(4.8)$ & $20(5)$ & 1.000 \\
\hline Unknown & $178(42.5)$ & $10(47.6)$ & $168(42.2)$ & 0.656 \\
\hline
\end{tabular}

Figures are numbers with percentages in parentheses or means \pm SD unless otherwise stated. ASA = Acetylsalicylic acid; ERDP = extended-release dipyridamole.

variant in $17 \%$ of 82 PCAI patients. Examination of this variant is important since secondary prophylaxis, e.g. in case of a higher-grade symptomatic stenosis of the internal carotid artery feeding the fetal PCA, is affected.

Patients with supratentorial PCAI had a significantly lower baseline NIHSS score compared to group 2, while rates of independent and favorable clinical outcome at 3 months did not differ between the 2 groups. This may be explained by the fact that symptoms of supratentorial PCAI are undervalued by the NIHSS but nevertheless influence functional outcome, comparable to symptoms caused by anterior circulation strokes. Thus, even though 


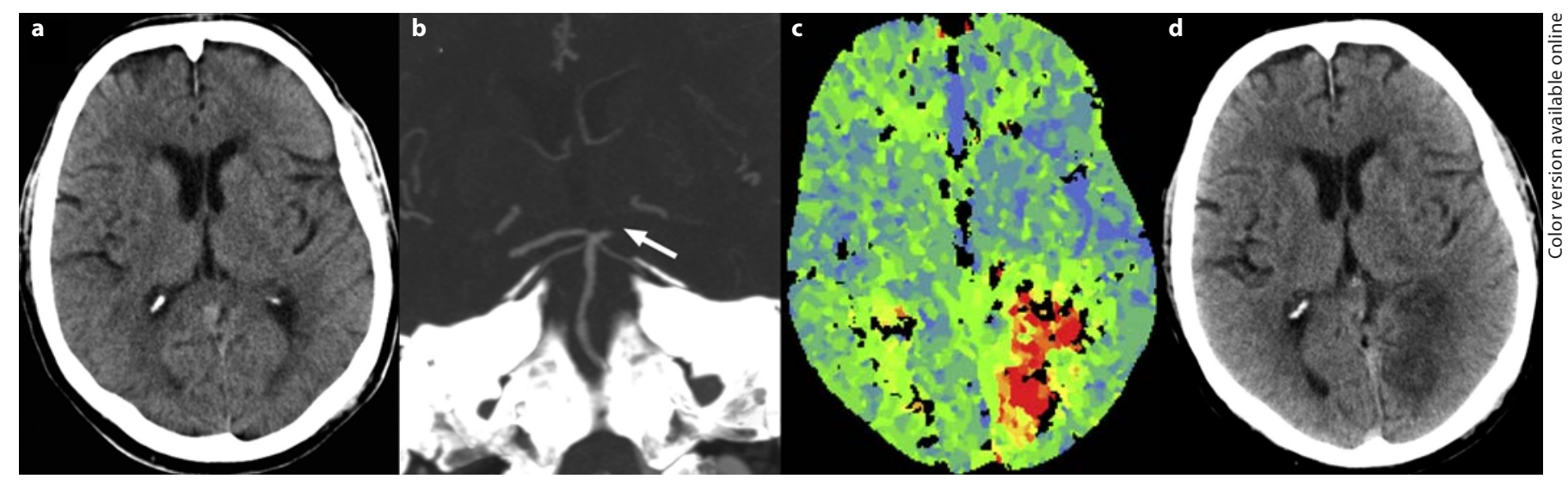

Fig. 1. Case presentation. a-c Pretreatment CT (a) of an 82-yearold man presenting to the emergency room with clinically suspected left-sided MCA territory stroke (severe aphasia, right-sided facial palsy and hemiparesis). Further examination revealed complete hemianopia to the right side. CT angiography (b) and
CT perfusion imaging (c) demonstrate left-sided PCA occlusion and a corresponding extended perfusion deficit. $\mathbf{d}$ Post-treatment CT after unsuccessful thrombolysis with $63 \mathrm{mg}$ tissue plasminogen activator (within $100 \mathrm{~min}$ of symptom onset) showing ischemic infarction in the left PCA territory.

Table 3. Outcome and safety data

\begin{tabular}{lllll}
\hline & $\begin{array}{l}\text { All infarcts } \\
\text { (PCA/MCA/ACA }) \\
(\mathrm{n}=419)\end{array}$ & $\begin{array}{l}\text { PCAI } \\
(\mathrm{n}=21)\end{array}$ & $\begin{array}{l}\text { MCA/ACA } \\
\text { infarcts } \\
(\mathrm{n}=398)\end{array}$ & $\begin{array}{l}\mathrm{p} \\
\text { values }\end{array}$ \\
\hline $\begin{array}{l}\text { Outcome at 3 months } \\
\quad \text { Favorable clinical outcome }\end{array}$ & $203(49.0)$ & $12(57.1)$ & $191(48.6)$ & 0.445 \\
$\begin{array}{l}\text { Hemorrhagic complications } \\
\text { aICH }\end{array}$ & $29(6.9)$ & $2(9.5)$ & $27(6.8)$ & 0.649 \\
$\quad 14(3.3)$ & 0 & $14(3.5)$ & 0.632 \\
$\begin{array}{l}\text { Median length of hospital stay, days } \\
\text { Mortality at 3 months }\end{array}$ & $8[6-12]$ & $8[6.5-10]$ & $8[6-12]$ & 0.477 \\
\hline
\end{tabular}

Figures in parentheses are percentages; figures in brackets are ranges.

patients with PCAI had lower NIHSS scores, this does not mean that they were functionally less affected. Often, treating physicians are hesitant to perform IVT in the case of low NIHSS scores. However, taking the disabling character of e.g. isolated complete hemianopia into account, treatment decision should be based on considerations regarding functional impairment of the symptoms rather than solely on a particular NIHSS score [21]. This also applies to the design of inclusion criteria of acute stroke studies.

Our study has obvious limitations, most notably the retrospective, observational design. Furthermore, the in- vestigated number of IVT-treated PCAI is small. In addition, since according to international guidelines [19] treatment was based on non-contrast CT only in the majority of cases, we could not assess recanalization data. Because of the differing sample size, statistical comparisons between group 1 and group 2 are difficult and results must be interpreted with caution. However, to our knowledge, this is the first systematical analysis of IVT in supratentorial PCA strokes.

In conclusion, our results do not suggest any substantial differences regarding safety and outcome between IVT in PCAI and anterior circulation infarcts. Thus, di- 
agnostics to firmly identify those patients do not seem required before IVT. Taking the naturally lower NIHSS scores in PCAI with nevertheless functionally disabling syndromes into account, indication for IVT and inclusion into clinical trials should be based on considerations of the functional impact of PCAI symptoms rather than solely on a specific NIHSS score.

\section{Disclosure Statement}

M.K. and H.B.H. received travel grants from Boehringer Ingelheim, the producer of recombinant tissue plasmonigen activator.

\section{References}

1 Kleihues P, Hizawa K: The infarct of the posterior cerebral artery: pathogenesis and topographical relationship to the visual cortex. Arch Psychiatr Nervenkr 1966;208:263284

2 Cals N, Devuyst G, Afsar N, Karapanayiotides T, Bogousslavsky J: Pure superficial posterior cerebral artery territory infarction in the Lausanne Stroke Registry. J Neurol 2002;249:855-861.

3 Kumral E, Bayulkem G, Atac C, Alper Y: Spectrum of superficial posterior cerebral artery territory infarcts. Eur J Neurol 2004; 11:237-246

4 Steinke W, Mangold J, Schwartz A, Hennerici M: Mechanisms of infarction in the superficial posterior cerebral artery territory. J Neurol 1997;244:571-578.

5 Yamamoto Y, Georgiadis AL, Chang HM, Caplan LR: Posterior cerebral artery territory infarcts in the New England Medical Center Posterior Circulation Registry. Arch Neurol 1999;56:824-832.

6 Brandt T, Thie A, Caplan LR, Hacke W: Infarcts in the brain areas supplied by the posterior cerebral artery. Clinical aspects, pathogenesis and prognosis. Nervenarzt 1995;66:267-274

7 Caplan LR, DeWitt LD, Pessin MS, Gorelick PB, Adelman LS: Lateral thalamic infarcts. Arch Neurol 1988;45:959-964.

8 Fisher CM: The posterior cerebral artery syndrome. Can J Neurol Sci 1986;13:232239.

9 Goto K, Tagawa K, Uemura K, Ishii K, Takahashi S: Posterior cerebral artery occlusion: clinical, computed tomographic, and angiographic correlation. Radiology 1979;132: 357-368.

10 Graff-Radford NR, Damasio H, Yamada T, Eslinger PJ, Damasio AR: Nonhaemorrhagic thalamic infarction. Clinical, neuropsychological and electrophysiological findings in four anatomical groups defined by computerized tomography. Brain 1985;108:485-516.

11 Hebel N, von Cramon DY: On the posterior infarct. Fortschr Neurol Psychiatr 1987;55: 37-53.

12 Milandre L, Brosset C, Botti G, Khalil R: A study of 82 cerebral infarctions in the area of posterior cerebral arteries. Rev Neurol (Paris) $1994 ; 150: 133-141$
13 Hafeez F, Levine RL, Dulli DA, Razzaq MA Differing mechanisms between posterior and middle cerebral artery infarctions. J Stroke Cerebrovasc Dis 1998;7:250-254.

14 Brandt T, Steinke W, Thie A, Pessin MS, Caplan LR: Posterior cerebral artery territory infarcts: clinical features, infarct topography, causes and outcome. Multicenter results and a review of the literature. Cerebrovasc Dis $2000 ; 10: 170-182$.

15 Hacke W, Kaste M, Fieschi C, Toni D, Lesaffre E, von Kummer R, Boysen G, Bluhmki E, Hoxter G, Mahagne MH, et al: Intravenous thrombolysis with recombinant tissue plasminogen activator for acute hemispheric stroke. The European Cooperative Acute Stroke Study (ECASS). JAMA 1995;274: 1017-1025.

16 Hacke W, Kaste M, Fieschi C, von Kummer R, Davalos A, Meier D, Larrue V, Bluhmki E, Davis S, Donnan G, Schneider D, Diez-Tejedor E, Trouillas P: Randomised double-blind placebo-controlled trial of thrombolytic therapy with intravenous alteplase in acute ischaemic stroke (ECASS II). Second European-Australasian Acute Stroke Study Investigators. Lancet 1998;352:1245-1251.

17 Hacke W, Kaste M, Bluhmki E, Brozman M, Davalos A, Guidetti D, Larrue V, Lees KR, Medeghri Z, Machnig T, Schneider D, von Kummer R, Wahlgren N, Toni D: Thrombolysis with alteplase 3 to $4.5 \mathrm{~h}$ after acute ischemic stroke. N Engl J Med 2008;359:13171329

18 Adams HP Jr, Bendixen BH, Kappelle LJ, Biller J, Love BB, Gordon DL, Marsh EE 3rd: Classification of subtype of acute ischemic stroke. Definitions for use in a multicenter clinical trial. TOAST. Trial of Org 10172 in Acute Stroke Treatment. Stroke 1993;24:3541.

19 European Stroke Organisation (ESO) Executive Committee, ESO Writing Committee: Guidelines for management of ischaemic stroke and transient ischaemic attack 2008. Cerebrovasc Dis 2008;25:457-507.
20 Adams HP Jr, del Zoppo G, Alberts MJ, Bhatt DL, Brass L, Furlan A, Grubb RL, Higashida RT, Jauch EC, Kidwell C, Lyden PD, Morgenstern LB, Qureshi AI, Rosenwasser RH, Scott PA, Wijdicks EF: Guidelines for the early management of adults with ischemic stroke: a guideline from the American Heart Association/American Stroke Association Stroke Council, Clinical Cardiology Council, Cardiovascular Radiology and Intervention Council, and the Atherosclerotic Peripheral Vascular Disease and Quality of Care Outcomes in Research Interdisciplinary Working Groups: the American Academy of Neurology affirms the value of this guideline as an educational tool for neurologists. Stroke 2007;38:1655-1711.

21 Kohrmann M, Nowe T, Huttner HB, Engelhorn T, Struffert T, Kollmar R, Saake M, Doerfler A, Schwab S, Schellinger PD: Safety and outcome after thrombolysis in stroke patients with mild symptoms. Cerebrovasc Dis 2009:27:160-166.

22 Breuer L, Schellinger PD, Huttner HB, Halwachs R, Engelhorn T, Doerfler A, Kohrmann M: Feasibility and safety of magnetic resonance imaging-based thrombolysis in patients with stroke on awakening: initial single-centre experience. Int J Stroke 2010;5: 68-73.

23 Pessin MS, Lathi ES, Cohen MB, Kwan ES, Hedges TR 3rd, Caplan LR: Clinical features and mechanism of occipital infarction. Ann Neurol 1987;21:290-299.

24 Tao WD, Kong FY, Hao ZL, Lin S, Wang DR, Wu B, Liu M: One-year case fatality and disability after posterior circulation infarction in a Chinese hospital-based stroke study. Cerebrovasc Dis 2010;29:376-381.

25 Yang JH, Choi HY, Nam HS, Kim SH, Han SW, Heo JH: Mechanism of infarction involving ipsilateral carotid and posterior cerebral artery territories. Cerebrovasc Dis 2007;24:445-451.

26 Maulaz AB, Bezerra DC, Bogousslavsky J: Posterior cerebral artery infarction from middle cerebral artery infarction. Arch Neurol 2005;62:938-941.

27 Lee E, Kang DW, Kwon SU, Kim JS: Posterior cerebral artery infarction: diffusion-weighted MRI analysis of 205 patients. Cerebrovasc Dis 2009;28:298-305. 
28 Pessin MS, Kwan ES, DeWitt LD, Hedges TR 3rd, Gale D, Caplan LR: Posterior cerebral artery stenosis. Ann Neurol 1987;21:85-89.

29 Bruno A, Levine SR, Frankel MR, Brott TG, Lin Y, Tilley BC, Lyden PD, Broderick JP, Kwiatkowski TG, Fineberg SE: Admission glucose level and clinical outcomes in the NINDS rt-PA stroke trial. Neurology 2002; 59:669-674.

30 Kase CS, Furlan AJ, Wechsler LR, Higashida RT, Rowley HA, Hart RG, Molinari GF, Frederick LS, Roberts HC, Gebel JM, Sila CA, Schulz GA, Roberts RS, Gent M: Cerebral hemorrhage after intra-arterial thrombolysis for ischemic stroke: the PROACT II trial. Neurology 2001;57:1603-1610.
31 Els T, Klisch J, Orszagh M, Hetzel A, SchulteMonting J, Schumacher M, Lucking CH: Hyperglycemia in patients with focal cerebral ischemia after intravenous thrombolysis: in fluence on clinical outcome and infarct size. Cerebrovasc Dis 2002;13:89-94.

32 Demchuk AM, Morgenstern LB, Krieger DW, Linda Chi T, Hu W, Wein TH, Hardy RJ, Grotta JC, Buchan AM: Serum glucose level and diabetes predict tissue plasminogen activator-related intracerebral hemorrhage in acute ischemic stroke. Stroke 1999;30:34-39.

33 Tissue plasminogen activator for acute ischemic stroke. The National Institute of Neurological Disorders and Stroke rt-PA Stroke Study Group. N Engl J Med 1995;333:15811587.
34 Wahlgren N, Ahmed N, Davalos A, Ford GA, Grond M, Hacke W, Hennerici MG, Kaste M, Kuelkens S, Larrue V, Lees KR, Roine RO, Soinne L, Toni D, Vanhooren G: Thrombolysis with alteplase for acute ischaemic stroke in the Safe Implementation of Thrombolysis in Stroke-Monitoring Study (SITS-MOST): an observational study. Lancet 2007;369: 275-282.

35 Caplan L: Posterior circulation ischemia: then, now, and tomorrow. The Thomas Willis Lecture-2000. Stroke 2000;31:2011-2023.

36 de Monye C, Dippel DW, Siepman TA, Dijkshoorn ML, Tanghe HL, van der Lugt A: Is a fetal origin of the posterior cerebral artery a risk factor for TIA or ischemic stroke? A study with 16-multidetector-row CT angiography. J Neurol 2008;255:239-245. 